Ли Сюй-кандидат политических наук, старший преподаватель Института марксизма ВосточноКитайского университета политологии и права (200042, Китай, г. Шанхай, ул. Вань Хан Ду, 1575; lixu1210@rambler.ru)

\title{
СОВЕРШЕНСТВОВАНИЕ МЕХАНИЗМА БОРЬБЫ С КОРРУПЦИЕЙ В ВЫСШИХ УЧЕБНЫХ ЗАВЕДЕНИЯХ КИТАЯ В НОВЫХ УСЛОВИЯХ
}

\begin{abstract}
Аннотация. Статья посвящена проблеме коррупции в системе высшего образования Китайской Народной Республики. Автор выявляет основные причины ее возникновения и распространения в колледжах и университетах Китая (с приведением соответствующих примеров) и определяет специфику коррупции в вузах на современном этапе развития китайского общества. В статье проводится анализ сложившейся к настоящему времени законодательной базы высшего образования и дается оценка ее антикоррупционного потенциала. Автор кратко характеризует основные теории борьбы с коррупционными преступлениями, предлагающиеся в современной китайской юриспруденции и социологии, и формулирует ряд предложений по совершенствованию механизма борьбы с коррупцией.
\end{abstract}

Ключевые слова: коррупция, высшие учебные заведения, Китай, механизм регулирования и борьбы, наказание, система

Актуальность проблемы. Коррупция - сложное социальное явление, подобное костному наросту. В ходе развития человеческой цивилизации коррупцию всегда было трудно устранить. Так, основатель династии Мин император Чжу Юаньчжан, борясь с коррупцией, учредил жестокие пытки (в т.ч. пытку «очищение травой») для наказания коррупционных преступлений. Однако впоследствии этот император признавался, что с коррупцией ничего нельзя поделать: «Я стремлюсь схватить алчных, порочных чиновников, но при этом совершаю преступления и убиваю».

Обращаясь к современности, необходимо констатировать, что коррупция получила распространение во многих сферах китайского общества. И даже университеты Китайской Народной Республики (КНР), известные как «башни из слоновой кости», не смогли избежать этого явления. Высококачественное высшее образование в Китае всегда было и остается дефицитным ресурсом, что, в свою очередь, дает и нередко продолжает давать возможность возникновения и распространения коррупционных явлений в сфере высшего образования.

Коррупция в высших учебных заведениях оказывает серьезное негативное влияние на идеологию преподавателей, сотрудников и студентов, влияет на нормальное преподавание и порядок работы, по сути, ставя под угрозу механизм подготовки кадров в КНР и препятствуя «здоровому» - целенаправленному и системному - развитию высшего образования в стране.

Специфика коррупции в вузах на современном этапе. В новых условиях коррупция в высших учебных заведениях Китая имеет 3 основных характерных черты.

Во-первых, коррупция в колледжах и университетах получает все более широкое распространение и уже не является случайным, единичным явлением. Например, согласно статистическим данным Антикоррупционного бюро Народной прокуратуры в округе Хайдянь города Пекина, в период с 2002 по 2004 г. в сфере высшего образования было заведено 11 дел на 11 чел., что составило 7,6\% общего числа уголовных дел и $6,8 \%$ общего числа обвиняемых. В 2005 г. университетская система этого же округа подала иск по 
поводу 6 дел и 7 чел., что составило $30 \%$ общего числа дел и $23 \%$ общего числа обвиняемых за указанный год, а в период с января по июль 2006 г. университеты уже подали иск по поводу 7 дел и 8 чел., что, соответственно, составило 37\% и 38\% общего числа [Ван Чанлинь, Лян Юэ 2006: 45].

Во-вторых, большинство сотрудников, вовлеченных в дела о коррупции в вузах, являются основными ответственными лицами колледжей, департаментов, исследовательских институтов, лабораторий и т.П., вПлоть до руководителей образовательных учреждений, зачастую занимающих важные административные и научно-исследовательские посты.

В-третьих, неуклонно растут суммы взяток по делам о коррупции в высших учебных заведениях, что представляет собой более серьезный уровень коррупции и взяточничества и влечет за собой суровые уголовные наказания. Так, например, бывший вице-президент отдела науки и технологий провинции Чжецзян за взяточничество был приговорен к смертной казни (с отсрочкой исполнения наказания в 2 года), и все его имущество было конфисковано.

Следует отметить, что в целом китайское общество осознает огромный вред коррупции в высших учебных заведениях, поэтому механизм борьбы с коррупцией в КНР постоянно совершенствуется.

Законодательная база высшего образования КНР и ее антикоррупционный потенциал. Обращаясь к законодательно-правовой базе Китайской Народной Республики, необходимо указать, что современный государственный правовой кодекс КНР, обладая четко сформированными правовыми и системообразующими функциями, позволяет сформировать достаточно стабильную и надежную систему борьбы с коррупцией.

Напомним, что с 1980 г. в Китае принят ряд государственных законов и нормативных актов о высшем образовании, а также административных и ведомственных правил, местных нормативных актов и т.П. В частности, это Положение КНР об ученых степенях (1980), закон КНР о преподавании (1993), закон КНР об образовании (1995), закон КНР о профессиональном образовании (1996), закон КНР о высшем образовании (1998), закон КНР о развитии платного образования (2002) и др.

Вместе с тем при детальном анализе принятых в 1990-х - нулевых годах законов и положений об образовании в них можно обнаружить ряд недостатков.

Во-первых, они изобилуют политическими установками и общими формулировками и определениями, а пунктов, пригодных для практического осуществления, сравнительно мало, что нередко превращает эти законы и положения в «законы на бумаге» (law on paper), а не в «законы в действии» (law on action). Очевидно, что это значительно снижает эффективность реализации данных законов.

Во-вторых, отсутствие комплексных процессуальных регламентов и конкретных практических положений также негативно влияет на эффективное исполнение законов и нормативных актов.

В-третьих, нормативные акты высших учебных заведений отстают от практики, что приводит к пробелам в законодательстве. Разработка законов и нормативных актов в области высшего образования по-прежнему ориентируется на отношения «правительство - высшее образование» в традиционном смысле, игнорируя многочисленные новые проблемы, с которыми сталкиваются высшие учебные заведения в процессе перехода к управлению в качестве независимого юридического лица. Наконец, отсутствие четких положений о полномочиях и служебных обязанностях преподавателей и сотрудников университетов нередко приводит к конфликтам между политической, административной, академической властями и властью демократического управления; иными сло- 
вами, системы управления и механизмы функционирования университетов не взаимодействуют в одном ключе.

Основные положения современной китайской юриспруденци и социологии в связи с исследуемой проблемой. Сегодня в юриспруденции КНР однозначно признается, что эффективный судебный контроль над социальными явлениями зависит от 1) повышения вероятности обнаружения и 2) степени наказания. Первое позволяет поддерживать коэффициент преступности и правонарушений на более низком уровне, предотвращая надежды преступников на «счастливый случай», чтобы избежать наказания, второе ставит действующее лицо перед необходимостью нести определенную меру наказания (очевидно, что лицо, совершившее преступление, заинтересовано в минимальной степени наказания).

В ряде китайских колледжей и университетов были проведены исследования и практические мероприятия по разработке и внедрению механизма регулирования и борьбы с коррупцией согласно так называемым трем «нет» коррупции: 1) «не осмеливаться», 2) «не допускать», 3) «не желать коррупции», которые дали положительные результаты.

В социологии выделяют 3 основные стратегии борьбы с коррупцией.

Суть первой из них определяется тезисом: «мораль противодействует коррупции». Исходя из того, что решающим фактором возникновения и распространения коррупции является человеческая природа, требуется особое - «антикоррупционное» - воспитание и образование.

Как пишет Го Щицзе, «основная причина распространения коррупции кроется в извращенной системе ценностей человека: поклонении деньгам и крайней степени эгоцентризма» [Го Шицзе 2013: 77]. Коррупция непосредственно затрагивает отдельных лиц, которые оказываются внутренними факторами, занимающими решающее положение в причинно-следственной связи. Поэтому любая форма коррупции может иметь истоки в деградации здорового образа мыслей и упадке нравственности отдельных лиц. Возникновение и распространение коррупции в колледжах и университетах имеет тесную связь с личностными факторами, прежде всего с психологическим дисбалансом индивидуумов. Большинство преподавателей и сотрудников высших учебных заведений имеют высшее образование, высокий уровень знаний, однако механизм распределения доходов и их объем, определяемый типом конкретного образовательного учреждения, не всегда, по мнению персонала учебных заведений, адекватны затратам труда в учебном процессе. Поэтому наиболее эффективная, по мнению ряда социологов, стратегия регулирования и борьбы с коррупцией должна опираться на соответствующее образование, нравственное просвещение, развитие и совершенствование интеллекта, пропаганду и популяризацию культурно-нравственных ценностей и т.д.

Сторонники второй стратегии считают, что «ужесточение наказания противодействует коррупции». В условиях достаточно широкого распространения коррупции ключевой проблемой, по их мнению, является недостаточность меры юридического наказания, поэтому только «применение беспощадных законов обуздает мировой хаос». Следует опираться на расширение нормативно-правовых положений для контроля коррупции, усилить меры наказания за любые коррупционные действия - именно это позволит эффективно бороться с коррупцией и победить ее.

Содержание третьей стратегии связано с применением «комплексных мер противодействия коррупции». Сторонники данной точки зрения совершенно справедливо считают, что причины возникновения и распространения коррупции могут быть самыми различными, и поэтому, для того чтобы эффективно бороться с коррупцией, необходимо сочетать преимущества «идейно-нрав- 
ственного противодействия коррупции» и «противодействия коррупции путем ужесточения наказания».

Предложения по совериенствованию механизма борьбы с коррупцией в вузах. Как уже указывалось, в последние годы борьба с коррупцией в колледжах и университетах Китая непрерывно растет. Расследован ряд дел о коррупции, привлечены к ответственности вовлеченные в коррупцию сотрудники учебных заведений, однако случаи коррупции в отдельных вузах Китая, по мнению специалистов [Ван Чанлинь, Лян Юэ 2006: 45; Го Шицзе 2013: 77; Лю Шоуфэнь, Сюй Даомин 2000], все-таки пока еще распространены.

Чтобы эффективно регулировать борьбу с коррупцией в высших учебных заведениях, необходимо повысить вероятность выявления случаев коррупции, снизить потенциальную возможность совершения преступления коррупционерами. Для этого следует, во-первых, усилить ответственность партийных комитетов вузов, выделить функцию контроля за соблюдением дисциплины и привлечения к ответственности. Будучи начальным и основным действующим лицом, с которого начинается возбуждение и расследование дел о коррупции в вузах, в новых условиях партийные комитеты должны активно участвовать в строительстве честного и неподкупного управляющего аппарата в колледжах и университетах, обобщая эффективный опыт, расширяя деловые возможности и т.П. Иными словами, партийные комитеты вузов должны играть если не главную, то важную роль в выявлении и расследовании случаев коррупции и осуществлении соответствующих карательных мер (наказаний).

Вместе с тем предотвращение коррупции (т.е. осуществление превентивных мер) должно быть содержанием деятельности как партийных комитетов, так и административного аппарата высших учебных заведений; при этом основная ответственность, по нашему мнению, должна лежать на партийных комитетах.

Во-вторых, необходимо помочь преподавателям, учебно-вспомогательному персоналу и студенческим группам высших учебных заведений признать свой статус полновластных хозяев, повысить их осознание участия в жизни своего учебного заведения, развития в нем демократии, поддержания порядка и контроля.

В университетах и колледжах КНР уровень культуры и чувство демократии преподавателей, персонала и студентов, как правило, высокие; понимание ими важности порядка и контроля также сравнительно сильное, т.к. они являются членами таких организаций, как профсоюзы преподавателей и служащих, студенческие союзы и т.П. Поэтому и преподаватели, и сотрудники, и студенты самым тесным образом связаны с расследованием дел о коррупции в вузах и могут предоставить соответствующую информацию и улики при расследовании коррупции в колледжах и университетах, что способствует повышению вероятности раскрытия коррупционных преступлений.

И, наконец, в-третьих, повышение вероятности раскрытия случаев коррупции в высших учебных заведениях неотделимо от эффективного массового контроля за общественным мнением. Комитеты по надзору за соблюдением дисциплины в вузах (в дополнение к установленной отчетности по телефонным разговорам, разговорам вне помещений, простой и электронной почтовой переписке, факсам и специальным приемам посетителей) должны уделить особое внимание новой форме контроля - интернет-контролю. Надзор за Сетью был утвержден еще в 2010 г. и занесен в Белую книгу (сборник официальных документов) в качестве задачи по созданию антикоррумпированного, честного и неподкупного аппарата. Сегодня надзор осуществляется в основном за фоновой сетевой информацией, использующей Интернет в качестве платформы для предоставления информации о соответствующем случае или информирования 
соответствующих участников через электронные доски объявлений, системы информационных табло, виртуальные сообщества и другие электронные информационные базы данных. Кроме того, чтобы поощрять контроль общественного мнения, вузам следует уделять внимание случаям утечки информации, предоставляя осведомителям и информаторам соответствующее материальное и моральное вознаграждение.

Усиление строгости наказания по коррупционным делам в высших учебных заведениях - еще одна составляющая процесса совершенствования борьбы с коррупцией. Настойчивое требование усилить суровость наказания по коррупционным делам в высших учебных заведениях не означает одобрения «смертной казни за коррупцию». Оно предполагает «соразмерное наказание за преступление», основанное на строгости и неуклонности наказания. Повышение строгости наказания за коррупционные действия, относящиеся к дисциплинарной, гражданской, административной или уголовной ответственности, подразумевает рациональное совершенствование мер наказания в соответствии с коррупционными действиями и обстоятельствами, формирование в отношении преступников сильных сдерживающих факторов и психологического давления.

Ограничение профессиональной деятельности, лишение прежнего социально-профессионального статуса и репутации выявленных коррупционеров при назначении им меры наказания вызывают особые одобрение и поддержку в китайском обществе.

Частота возникновения и распространения коррупционных явлений в высших учебных заведениях связаны и с недостатками самой системы образования. Как указывал Дэн Сяопин, «хорошая система может сделать плохих людей неспособными своевольничать и бесчинствовать. Плохая система может сделать хороших людей неспособными в полной мере творить хорошие дела, и даже перейти на противоположную сторону... Проблемы системы носят фундаментальный, всеобъемлющий, стабильный и долгосрочный характер» [Дэн Сяопин 1993a: 379]. Поэтому сегодня в рамках борьбы с коррупцией назрела острая необходимость совершенствования современной университетской системы.

Еще в 1985 г. в Решении ЦК Коммунистической партии Китая о реформе системы образования указывалось, что «расширение автономии высших учебных заведений» открыло занавес реформы китайской университетской системы. В 1993 г. ЦК КПК и Государственный совет Китая выпустили План реформы и развития образования в Китае, в соответствии с которым высшие учебные заведения КНР должны были приобрести статус социально независимых юридических лиц с правом самостоятельного управления.

Однако, по мнению некоторых ученых, несмотря на увеличение инвестиций в высшие учебные заведения Китая, чтобы придать им самостоятельность, и развитие университетов и колледжей, все-таки пока остающиеся ограничения университетской системы предопределяют не вполне удовлетворительные результаты в осуществлении реформы высшего образования, поэтому «сколько бы мы ни ходили кругами, мы все так же ощущаем потребность вернуться к строительству современной университетской системы» [Дун Юнчуань 2004: 136].

Чтобы усовершенствовать современную университетскую систему в КНР, важнее всего выдвинуть на первый план именно единство прав и обязанностей. В этом смысле как никогда актуальны слова Дэн Сяопина: «В структуре управления предприятиями длительный период отсутствуют строгие административные законы и нормы и система ответственности сверху донизу. Не хватает строгого и четкого определения прав и обязанностей каждой организации 
и каждого человека, вплоть до того, что, каким бы ни было дело, неясно, кто им должен руководить» [Дэн Сяопин 1993б: 328].

Очевидно, что в высших учебных заведениях, не имеющих современной университетской системы управления, отсутствует эффективный надзор, вследствие чего распространена коррупция.

Сегодня университеты обладают большой автономией в сфере зачисления студентов, управления научно-исследовательскими фондами, закупки товаров и приглашения на работу персонала. Но при этом расширение полномочий, ответственность и надзор все же не в компетенции высших учебных заведений. Университеты для удовлетворения потребностей общества вынуждены создавать учебные курсы коммерческого характера, учреждать независимые колледжи и другие организации, в которых зачастую существуют такие явления, как неопределенность и неясность обязанностей, прав и ответственности, что создает питательную среду для коррупции. Поэтому, претворяя в жизнь единство прав и обязанностей, система управления в каждом учебном заведении и в каждой административной единице всех рангов должна четко определить круг обязанностей в отношении людей, денежных средств и имущества, создать систему должностной ответственности в сфере преподавания и управления, разграничить должностные права и обязанности, в точности установить механизм контроля ограничений, определить соответствующие нормативы должностной ответственности и т.д.

Вместе с тем не следует пренебрегать важной ролью аудиторских организаций: справедливая и объективная аудиторская работа часто может предотвратить возникновение коррупционных проблем и/или обнаружить их источник.

Для совершенствования современной университетской системы с единством прав и обязанностей необходимо также ослабить административный стиль руководства в высших учебных заведениях. Ослабление административного стиля предполагает разграничение управления и контроля за преподавательской и научно-исследовательской деятельностью. Необходимо, опираясь на различия между административным управлением, с одной стороны, и научной и преподавательской деятельностью - с другой, спроектировать разные системы управления, с тем чтобы административная власть, обладающая административными функциями, и академическая власть, не обладающая административными качествами и функциями, могли действовать в сфере науки каждая сама по себе. Это поможет избежать профессиональных барьеров в административном управлении, а также позволит академическим силам получить больше свободы в своей специализации и создать по-настоящему благоприятные условия функционирования как в области административного управления, так и в сфере научных исследований.

Для предотвращения и ликвидации коррупции требуется также сформировать открытую и справедливую систему открытости информации. В большинстве случаев коррупция в высших учебных заведениях происходит в области тендеров на капитальное строительство, закупок учебных материалов, оборудования и услуг, а также зачисления учащихся. Эти сферы носят относительно скрытый и приватный характер, поэтому надзор и контроль на практике реализуются недостаточно. Как писал французский философ Ш. Монтескье, «все обладающие властью чиновники легко злоупотребляют ею, это раз и навсегда установленная истина» [Монтескье 1993: 76].

Абсолютная власть ведет к абсолютной коррупции. Лучшее «противоядие» от коррупции - поместить власть имущих «под солнечный свет», создать открытую и справедливую систему открытости информации с полностью прозрачным функционированием властных структур. Внедрение открытой и справедливой 
системы информации в высших учебных заведениях в областях повышенного риска и в ключевых сферах может, с одной стороны, максимально повысить прозрачность деятельности власти, предотвратить поиск личной выгоды в вузах, устранить возможность появления и распространения коррупционных действий. С другой стороны, это также приведет к тому, что преподаватели и студенты будут пристально следить за гласностью в соответствующих областях и на соответствующих уровнях, и это будет стимулировать энтузиазм сотрудников и студентов в деле изобличения, обуздания, сокращения распространения и предотвращения коррупции.

В рамках реформы высшего образования в Китае в последние годы предпринимаются определенные меры по обеспечению доступности информации. Так, в «Мерах по обеспечению доступности информации в высших учебных заведениях» (2010) перечислены основные составляющие доступности информации об университетах, в т.ч. финансы, активы и система управления финансами, источники финансирования учебных заведений, годовая смета расходов и проект годового финансового отчета, фонды финансирования, использование и управление пожертвованными средствами, закупка научного оборудования, инвентаря, книг, медикаментов и других материальных средств, а также важные тендеры на капитальное строительство и инфраструктуру. Другим важным документом стали «Основные требования к разглашению содержания информации в высших учебных заведениях», направленные на практическое решение задач по формированию системы доступности информации в высших учебных заведениях. Среди документов, регулирующих отдельные, конкретные вопросы работы вузов (например, прием учащихся), можно назвать «Уведомление о дальнейшем содействии открытости информации о поступлении в вузы» и др.

Следует признать, что, как уже отмечалось выше, действующие в Китае законы и нормативные акты в области высшего образования имеют определенные недочеты. Поэтому крайне важно осуществить целенаправленные законодательные действия, включая отмену устаревших законов (или отдельных разделов и пунктов в них); доработку/дополнение имеющихся и создание новых законодательных и нормативных актов в соответствии с практическими потребностями университетов и колледжей на современном этапе развития. В частности, считаем необходимым собрать воедино разбросанные в различных законах и нормативных актах положения, касающиеся коррупции в вузах, и провести их системную детализацию. В этом случае, с одной стороны, может быть исчерпывающе раскрыта руководящая функция закона, а с другой - это поможет каждому высшему учебному заведению разработать соответствующие внутренние положения, правила в соответствии со спецификой и новыми особенностями проведения внутренних реформ в рамках борьбы с коррупцией.

В деле борьбы с коррупцией в высших учебных заведениях дисциплинарные и судебные меры в большей мере имеют превентивное значение, играя роль предостережения. После возбуждения дела о коррупции к виновному применяется судебное наказание с тем, чтобы одновременно предостеречь потенциального преступника от рецидива.

В заключение назовем основные сформулированные и обоснованные в статье предложения по совершенствованию механизма борьбы с коррупцией в высших учебных заведениях Китая в новых условиях. Это:

1) расширение (дополнение) нормативно-правового обеспечения высшего образования в антикоррупционном аспекте;

2) реформирование университетской системы в плане укрепления целостности прав и обязанностей; 
3) создание справедливой и точной системы доступности информации с целью обнаружения фактов коррупции в вузах;

4) своевременное расследование и усиление степени наказания как превентивные меры, предупреждающие потенциальных участников об опасности вовлечения в коррупционные действия;

5) осуществление идейно-нравственного воспитания граждан для создания своего рода «антикоррупционного барьера» в их сознании и поведении согласно так называемым трем «нет» коррупции: «не осмеливаться», «не допускать», «не желать».

И еще раз подчеркнем, что проблема борьбы с коррупцией - одна из важнейших на современном этапе развития системы высшего образования в Китае, и от успешности и оперативности ее решения зависит дальнейшее процветание и преуспевание Китая.

\section{Список литературы}

Ван Чанлинь, Лян Юэ. 2006. Характеристики и меры по предотвращению должностных преступлений в высших учебных заведениях в современных условиях. - Народная прокуратура. Вып. 18.

Го Шицзе. 2013. Уголовное регулирование борьбы с коррупцией. - Журнал Шеньчженьского университета. Сер. Гуманитарные и социальные науки. Вып. 2.

Дун Юнчуань. 2004. Об отношениях китайских университетов, правительства и общества. Куньмин: Изд-во Юннаньского университета.

Дэн Сяопин. 1993а. Избранные произведения Дэн Сяопина. Пекин: Народный издательский дом. Т. III.

Дэн Сяопин. 1993б. Избранные произведения Дэн Сяопина. Пекин: Народный издательский дом. Т. II.

Лю Шоуфэнь, Сюй Даомин. 2000. Институциональная антикоррупционная теория. - Журнал Пекинского университета. Сер. Философия и социальные науки. Вып. 1.

Монтескье. 1993. Дух закона (пер. с франц. Чжан Яншена). Пекин: Коммерческая пресса. Т. I.

\section{THE IMPROVEMENT OF THE MECHANISM OF FIGHTING CORRUPTION IN HIGHER EDUCATION INSTITUTIONS OF CHINA WITHIN THE NEW CONDITIONS}

\footnotetext{
Abstract. The article is devoted to the problem of corruption in the higher education system of the People's Republic of China. The author identifies the main reasons of its occurrence and spread in colleges and universities of China (with relevant examples) and defines the specifics of corruption in universities at the present stage of development of Chinese society; analyzes the current legislative framework of higher education and assesses its anti-corruption potential. The author briefly describes the main theories of combating corruption crimes proposed in modern Chinese jurisprudence and sociology; and formulates a number of proposals to improve the mechanism of combating corruption.

Keywords: corruption, higher education institutions, China, mechanism of regulation and struggle, punishment, system
} 